\title{
Fragment-Based Discovery of 6-Arylindazole JAK Inhibitors
}

\author{
Andreas Ritzén, ${ }^{* \dagger}{ }^{\dagger}$ Morten D. Sørensen, ${ }^{\dagger}$ Kevin N. Dack, ${ }^{\dagger}$ Daniel R. Greve, ${ }^{\dagger}$ Anders Jerre, ${ }^{\dagger}$ \\ Martin A. Carnerup, ${ }^{\dagger}$ Klaus A. Rytved, ${ }^{\S}$ and Jesper Bagger-Bahnsen"
}

${ }^{\dagger}$ Drug Design, ${ }^{\ddagger}$ In Vitro Biology, ${ }^{\S}$ Skin PK and Early Safety, and "Preformulation \& Early Analytical Development, Global R\&D, LEO Pharma A/S, Industriparken 55, DK-2750 Ballerup, Denmark

\section{Supporting Information}

ABSTRACT: Janus kinase (JAK) inhibitors are emerging as novel and efficacious drugs for treating psoriasis and other inflammatory skin disorders, but their full potential is hampered by systemic side effects. To overcome this limitation, we set out to discover soft drug JAK inhibitors for topical use. A fragment screen yielded an indazole hit that was elaborated into a potent JAK inhibitor using structure-based design. Growing the fragment by installing a phenol moiety in the 6-position afforded a greatly improved potency. Fine-tuning the substituents on the phenol and sulfonamide moieties afforded a set of compounds with lead-like properties, but they were found to be phototoxic and unstable in the presence of light.

KEYWORDS: Fragments, JAK inhibitors, psoriasis, indazoles, phototoxicity

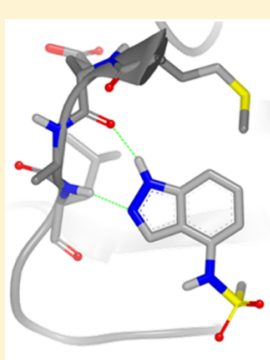

Fragment hit $\mathrm{JAK}_{1} \mathrm{pIC}_{50}=4.5$ $\mathrm{LE}=0.45$

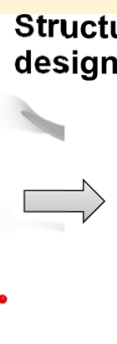

-based

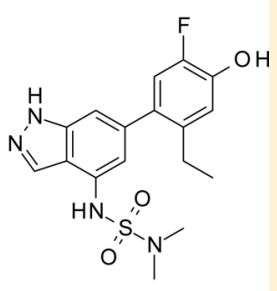

Lead

$\mathrm{JAK} 1 \mathrm{plC}_{50}=8.4$

Cell $\mathrm{plC}_{50}=7.0$

LE $=0.45$
$\mathrm{P}$ soriasis is a debilitating and chronic skin disorder affecting as many as one in 25 adults in Europe and one in 50 in the US. ${ }^{1}$ A recent analysis of survey data from the National Psoriasis Foundation in the US showed that $52.3 \%$ of patients with psoriasis were dissatisfied with their treatment. ${ }^{2}$ An urgent need for safe and effective therapies clearly exists. Psoriasis is a $\mathrm{T}$ cell-mediated chronic skin inflammation resulting from a complex interplay between immune and skin cells. ${ }^{3}$ These cells communicate using soluble mediators, e.g., cytokines. ${ }^{4}$ Intracellular signaling relevant to psoriasis is relayed from cytokine receptors by the Janus kinase (JAK) family of tyrosine kinases. It consists of four members (JAK1, JAK2, JAK3, and TYK2) that, upon activation by cytokine receptors, phosphorylate signal transducers and activators of transcription (STATs). ${ }^{5}$ JAK inhibitors have been extensively investigated because of their potential to treat chronic inflammatory conditions, e.g., rheumatoid arthritis (RA), psoriasis, and atopic dermatitis (AD). ${ }^{6,7}$ Two selective JAK inhibitors have been approved by the FDA: Tofacitinib (Xeljanz) for treating RA and Ruxolitinib (Jakafi) for treating myelofibrosis and polycythemia vera. Both drugs have shown significant benefit in psoriasis in clinical trials, ${ }^{8}$ and Tofacitinib was also found to be effective in $\mathrm{AD} .{ }^{9,10}$ However, because of their immunosuppressant and anemic effects, systemic administration of these drugs may cause serious adverse events, e.g., infections, infestations, and decreased hemoglobin levels. ${ }^{11}$ Topical administration for the treatment of psoriasis has been investigated for both drugs. ${ }^{8}$ Percutaneous absorption into systemic circulation may still limit the surface area that can be treated, although lower systemic levels than after oral administration were found. ${ }^{12}$ To avoid systemic side effects while delivering an effective treatment for dermatology indications, we set out to discover a topical JAK family inhibitor that would be absorbed into the skin and rapidly metabolized once in the bloodstream; i.e., a soft drug. ${ }^{13}$

In order to identify novel JAK inhibitors we performed a fragment screen. A kinase-targeted library of ca. 500 fragments was screened against JAK2 at a single concentration $(100 \mu \mathrm{M})$ using SPR. Hits were validated by determination of $K_{\mathrm{D}}$ using SPR and determination of $\mathrm{IC}_{50}$ in a biochemical enzyme inhibition assay for JAK1. In general, a good correlation was observed between these two measurements suggesting that most fragments had little or no selectivity for JAK2 over JAK1. Because we targeted pan-JAK inhibitors, this result made us confident in the validity of the hits, and several fragments were progressed to X-ray crystallography. In particular, compound 1 appeared to afford an excellent starting point because of its compact size, available vectors, and good ligand efficiency (Figure 1). Although indazoles had been identified as viable

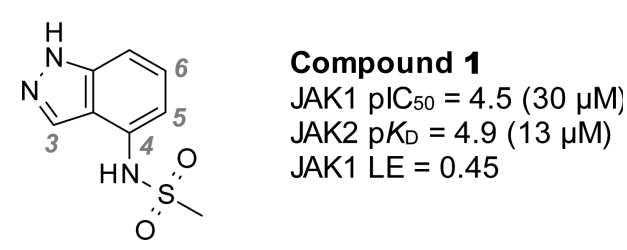

Figure 1. Fragment screen hit 1.

Received: February 26, 2016

Accepted: April 14, 2016

Published: April 14, 2016 
fragments for JAK2 previously, ${ }^{14}$ the sulfonamide moiety in the 4-position of 1 offered an unexplored handle. We envisioned that this feature in combination with fragment growth from other positions would yield potent and selective JAK inhibitors. Thus, we selected $\mathbf{1}$ for progression into hit-to-lead.

An X-ray crystal structure of $\mathbf{1}$ in complex with JAK2 was obtained, see Figure 2. Compound 1 occupies the purine region

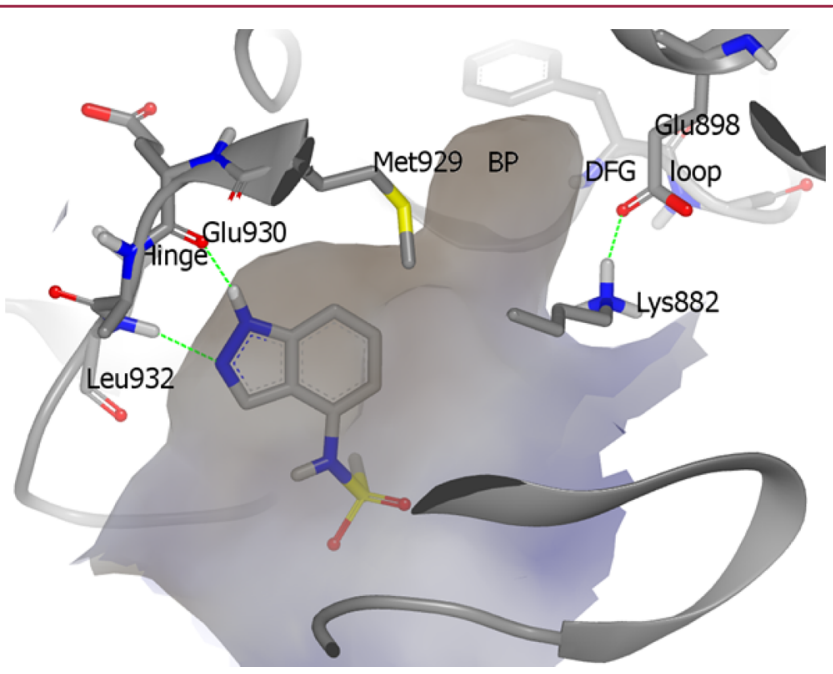

Figure 2. X-ray structure of compound 1 bound to JAK2 (PDB ID: 5L3A).

of the active site and makes two hydrogen-bonded contacts with the hinge residues Glu930 and Leu932. The binding mode of $\mathbf{1}$ is similar to that reported for other indazoles, but with an unfilled back pocket (BP) wider than previously observed. ${ }^{14}$ The widened back pocket in the structure of $\mathbf{1}$ is caused by a conformational change of Gly993 immediately preceding the DFG residues. We speculated that growing into this pocket might afford both potency and selectivity. To this end, we surveyed published JAK crystal structures in the PDB and identified two potent JAK2 inhibitors from Vertex with phenol moieties in the back pocket (PDB ID $3 \mathrm{JY}^{15}$ and $3 \mathrm{KCK}^{16}$ ). In contrast, a 6-phenylindazole had been reported to be virtually inactive in JAK2. ${ }^{14}$ This discrepancy can be attributed to a stabilizing hydrogen bond from the phenol hydroxyl group to Glu898.

As a first step to grow fragment 1 we set out to append a phenol moiety to the 6-position. This proposal was supported by docking a prototypical phenol-substituted indazole 2 into the literature JAK2 structure $3 \mathrm{KCK} .{ }^{16}$ We chose this structure for two reasons: the kinase backbone and active site side chains of $3 \mathrm{KCK}$ and the structure of $\mathbf{1}$ overlaid very well; and the crystallographic ligand 3 in $3 \mathrm{KCK}$ has a phenol in the back pocket. Comparison of the docked pose of 2 with the crystal structures of 1 and $3 \mathrm{KCK}$ showed that both the indazole moiety and the phenol moiety of $\mathbf{2}$ overlaid well with the corresponding moieties in the crystallographic ligands (Figure 3). All three ligands make similar hydrogen bonding interaction with the hinge residues Glu930 and Leu932. The phenols of 2 and 3 also make very similar hydrogen bonding interactions with the $\alpha \mathrm{C}$ helix residue Glu898 and the backbone $\mathrm{NH}$ of Phe995 in the DFG loop. The ligands do not directly interact with the catalytic lysine Lys 882 , but this residue is in contact with Glu898 in both structures. It is also worth noting that the gatekeeper Met929 is in close contact with the aromatic ring of

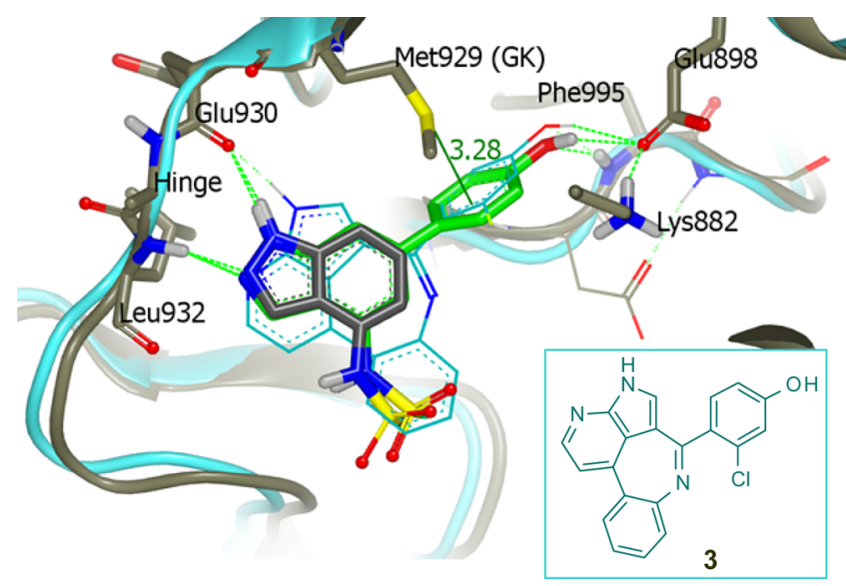

Figure 3. Model of phenol 2 (green) docked into the JAK2 structure $3 \mathrm{KCK}^{16}$ (cyan; crystallographic ligand 3 shown as wireframe) compared to the X-ray crystal structure of $\mathbf{1}$ (gray).

the phenol: the Met $S$ to aromatic ring centroid distance is 3.3 $\AA$. The geometry of this complex suggests a stabilizing $S \cdots \pi$ interaction. $^{17}$

On the basis of this analysis, we proceeded to synthesize phenol 2, see Scheme 1 . The key intermediate 5 was readily

Scheme 1. Synthesis of Phenol $2^{a}$
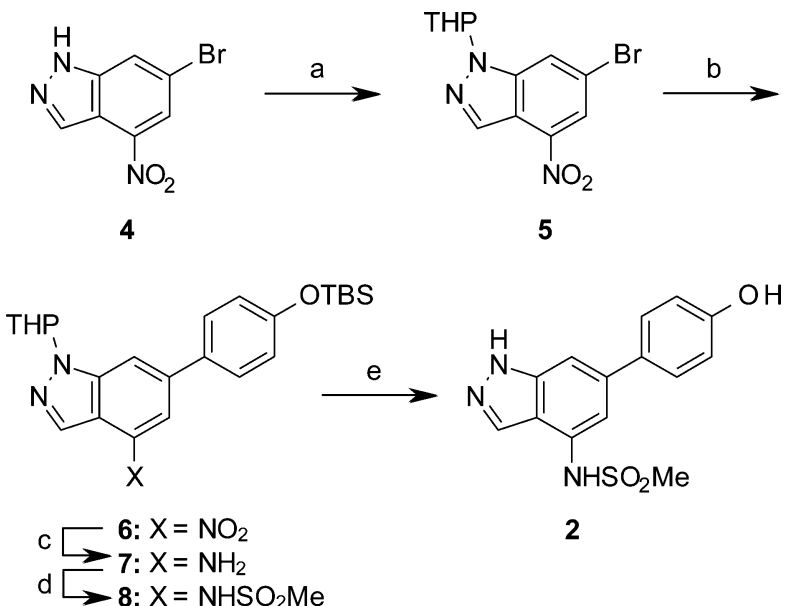

${ }^{a}$ Reagents and conditions: (a) DHP, PPTS, $\mathrm{CH}_{2} \mathrm{Cl}_{2}$, reflux, $3 \mathrm{~h}, 77 \%$; (b) 4-TBSO- $\mathrm{C}_{6} \mathrm{H}_{4}-\mathrm{B}(\mathrm{OH})_{2}, \mathrm{~K}_{2} \mathrm{CO}_{3}, \mathrm{Pd}(\mathrm{dppf}) \mathrm{Cl}_{2}, \mathrm{DMF}$, water, rt, $1 \mathrm{~h}$, 94\%; (c) Pd/C, $\mathrm{H}_{2}$ (1 bar), EtOAc, rt, 6 h, 58\%; (d) $\mathrm{MsCl}$, pyridine, $\mathrm{CH}_{2} \mathrm{Cl}_{2}, \mathrm{rt}, 3.5 \mathrm{~h}, 54 \%$; (e) $4 \mathrm{M} \mathrm{HCl}$ in dioxane, $\mathrm{MeOH}, \mathrm{rt}, 2 \mathrm{~h}, 71 \%$.

prepared from commercially available indazole $\mathbf{4}$ using standard conditions. Suzuki coupling with a TBS-protected phenol boronic acid afforded 6 , which upon nitro group reduction and reaction with methanesulfonyl chloride yielded the protected derivative 8. A global deprotection step furnished the desired phenol 2.

Gratifyingly, 2 exhibited greatly improved potency and also improved LE compared with fragment $\mathbf{1}$, see Table 1 . This compound also showed low micromolar activity in a cellular STAT6 reporter assay. Compound 2 appeared to be a good starting point for further optimization, and to this end, variations of the phenol and sulfonamide moieties were envisioned as the next steps. Considerations of the binding mode and the distance between these two moieties suggested that they could be optimized independently. Based on previous 
Table 1. Optimization of the Phenol Moiety ${ }^{a}$<smiles>[R]c1cc(O)c([R])c(-c2cc(N[SH]([R1])(=O)O)c3cn[nH]c3c2)c1[R]</smiles>

\begin{tabular}{|c|c|c|c|c|c|c|c|c|c|c|c|c|}
\hline \multirow[b]{2}{*}{ compd } & \multirow[b]{2}{*}{$\mathrm{R}^{1}$} & \multirow[b]{2}{*}{$\mathrm{R}^{2}$} & \multirow[b]{2}{*}{$\mathrm{R}^{3}$} & \multirow[b]{2}{*}{$\mathrm{R}^{4}$} & \multicolumn{2}{|l|}{ JAK1 } & \multirow[b]{2}{*}{ JAK2 } & \multirow[b]{2}{*}{ JAK3 } & \multirow[b]{2}{*}{ TYK2 } & \multicolumn{2}{|l|}{ cellular } & \multirow[b]{2}{*}{$\mathrm{S}+\log \mathrm{P}^{b}$} \\
\hline & & & & & $\mathrm{pIC}_{50}$ & LE & & & & $\mathrm{pIC}_{50}$ & LLE & \\
\hline 2 & $\mathrm{Me}$ & $\mathrm{H}$ & $\mathrm{H}$ & $\mathrm{H}$ & $7.47 \pm 0.09$ & 0.50 & 7.7 & 7.9 & n.d. & 5.4 & 3.5 & 1.9 \\
\hline 9 & Et & $\mathrm{H}$ & $\mathrm{H}$ & $\mathrm{H}$ & $7.43 \pm 0.06(2)$ & 0.47 & 8.0 & 8.1 & 6.4 & 5.7 & 3.5 & 2.3 \\
\hline 10 & Et & $\mathrm{Me}$ & $\mathrm{H}$ & $\mathrm{H}$ & $7.26 \pm 0.05$ & 0.44 & 7.5 & 7.6 & 6.1 & $5.78 \pm 0.02(2)$ & 3.4 & 2.4 \\
\hline 11 & Et & Et & $\mathrm{H}$ & $\mathrm{H}$ & $7.78 \pm 0.15(2)$ & 0.45 & 7.7 & 8.1 & 6.3 & 6.5 & 3.8 & 2.7 \\
\hline 12 & Et & $\mathrm{Cl}$ & $\mathrm{H}$ & $\mathrm{H}$ & $7.72 \pm 0.11(2)$ & 0.47 & 7.7 & 7.8 & 6.5 & $6.15 \pm 0.05$ & 3.4 & 2.8 \\
\hline 13 & Et & $\mathrm{H}$ & $\mathrm{Me}$ & $\mathrm{H}$ & $6.53 \pm 0.03$ & 0.40 & 6.9 & 7.2 & 6.1 & 5.5 & 2.9 & 2.6 \\
\hline 14 & Et & $\mathrm{H}$ & $\mathrm{Cl}$ & $\mathrm{H}$ & $7.15 \pm 0.11(2)$ & 0.44 & 7.7 & 7.9 & 6.6 & 6.0 & 3.1 & 2.9 \\
\hline 15 & Et & $\mathrm{H}$ & $\mathrm{F}$ & $\mathrm{H}$ & $7.54 \pm 0.11$ & 0.46 & 8.1 & 8.0 & 6.6 & $5.80 \pm 0.01(2)$ & 3.3 & 2.5 \\
\hline 16 & Et & $\mathrm{H}$ & $\mathrm{OMe}$ & $\mathrm{H}$ & $6.07 \pm 0.17(2)$ & 0.35 & 6.0 & 6.6 & 5.6 & $5.67 \pm 0.02(2)$ & 3.4 & 2.3 \\
\hline 17 & Et & $\mathrm{Me}$ & $\mathrm{H}$ & $\mathrm{Me}$ & $5.54 \pm 0.10$ & 0.32 & 5.7 & 5.6 & 5.2 & $4.60 \pm 0.03(2)$ & 1.9 & 2.7 \\
\hline 18 & $\mathrm{Me}$ & Et & $\mathrm{F}$ & $\mathrm{H}$ & 8.4 & 0.49 & 8.1 & 8.6 & n.d. & $6.40 \pm 0.03$ & 3.3 & $3.1^{c}$ \\
\hline 19 & Et & $\mathrm{Et}$ & F & $\mathrm{H}$ & $8.38 \pm 0.01$ & 0.47 & 8.3 & 8.6 & 6.8 & $6.77 \pm 0.03$ & 3.3 & $3.5^{c}$ \\
\hline
\end{tabular}

${ }^{a}$ Data given as $\mathrm{pIC}_{50}$ determined from single experiments with 10-point titration curves unless otherwise noted. Values from multiple determinations are given as mean \pm SEM $(N)$, where SEM is the standard error of the mean and $N$ is the number of replicates. Enzymatic assays: HTRF (Homogenous Time-Resolved Fluorescence) based kinase assay with ATP concentration at $K_{\mathrm{m}}$. Cellular assay: STAT6 reporter gene assay in a human B lymphocyte cell line (Ramos). ${ }^{b}$ Calculated using Simulations Plus, Inc. MedChem Designer. ${ }^{c}$ Experimentally determined log D at pH 7.4.

experience with other series of JAK inhibitors, we set criteria for a lead compound to be cellular $\mathrm{pIC}_{50} \geq 7$ and LLE $\geq 3$.

Expansion of the methyl sulfonamide to the ethyl derivative 9 afforded a slight increase in cellular potency with no change in LLE, see Table 1. Variations of the synthetic route shown in Scheme 1 were used to prepare the compounds in Tables 1 and 2; see Supporting Information for details. Compound 9 was chosen as the reference point for optimization of the phenol moiety. Inspection of the $3 \mathrm{KCK}$ structure showed that the chloro substituent of compound 3 filled a lipophilic subpocket lined by Val863 and the $\mathrm{C} \beta$-C $\delta$ methylenes of Lys882. Thus, the small, lipophilic substituents methyl, ethyl, and chloro were installed at position $\mathrm{R}^{2}$ to afford compounds 10, 11, and 12. All three compounds showed slight improvements in cellular potency with the ethyl analogue $\mathbf{1 1}$ being the best in terms of both potency and LLE. Next, the $\mathrm{R}^{3}$ position was probed with methyl, chloro, fluoro, and methoxy substituents (compounds 13-16). For reasons of synthetic expediency, the $R^{2}$ position was left unsubstituted in the hope that optimum substituents could be combined later. Compared with $\mathbf{9}$, moderate variations in enzymatic JAK1 and cellular STAT6 potency were observed for these derivatives with the halides $\mathbf{1 4}$ and $\mathbf{1 5}$ emerging as the best of these substituents.

Having explored the $\mathrm{R}^{2}$ and $\mathrm{R}^{3}$ positions, we set out to try various combinations of substituents. Because the phenol ring plane was twisted out of the plane of the indazole moiety in the docking pose of 2 (Figure 3), we prepared the dimethyl analogue 17 , which has a conformational preference for this geometry. Unfortunately, this compound showed poor activity, probably due to steric clashes with the protein. At this point, we became aware of a patent application claiming a series of indazole JAK inhibitors with no 4-substituents, but with substituted bicyclic heterocycles in the 3-position and phenols in the 6-position. ${ }^{18}$ Assuming that these indazoles bind with a similar binding mode to that of $\mathbf{2}$, the phenol substituent would be expected to overlap well between these two series. Interestingly, this publication suggested the combination of an $\mathrm{R}^{2}$ ethyl and an $\mathrm{R}^{3}$ fluoro substituent. Because this is consistent with the SAR we had already derived for these substituents, we proceeded to prepare this combination, both with a methyl (18) and ethyl sulfonamide (19). Compared with compound 11, the extra fluoro substituent of 19 afforded a slight improvement in both enzymatic JAK1 and cellular STAT6 potency. Similar to that which was observed when comparing 2 with 9, the ethyl derivative 19 had a slight edge over the methyl analogue $\mathbf{1 8}$ in terms of cellular potency with no change in enzymatic potency or LLE.

Armed with these results, we undertook an optimization of the sulfonamide substituent using $\mathbf{1 9}$ as the new reference compound, see Table 2. First, methylation of the free $\mathrm{NH}$ of the sulfonamide was investigated, but the resulting compound 20 showed a marked drop in potency compared with 19. Next, the small alkyl sulfonamides $\mathbf{2 1 - 2 4}$ and the trifluoromethane sulfonamide $\mathbf{2 5}$ were prepared and tested. Of these, the isopropyl (21) and cyclopropyl (22) analogues showed similar potency and lipophilicity compared to 19 , but none of these had any obvious advantage over 19. Because the sulfonamide is positioned at the solvent front of the active site, hydrophilic substituents were appended to the ethyl sulfonamide to improve solubility and reduce lipophilicity (compounds 2630). Unfortunately, all these analogues lost cellular potency to various degrees. Aromatic (31) and heteroaromatic (32, 33) substituents were also tried, but again, a loss of potency and LLE was observed for these analogues. However, the dimethylsulfamide 34, formally an aza analogue of 21 , showed improved cellular potency and LLE compared with both 19 and 21. Finally, a phosphinamide analogue 35 was prepared and 
Table 2. Optimization of the Sulfonamide Moiety ${ }^{a}$<smiles>[X]c1cc(-c2cc(F)c(O)cc2CC)cc2[nH]ncc12</smiles>

\begin{tabular}{|c|c|c|c|c|c|c|c|c|c|}
\hline \multirow{2}{*}{ Compound } & \multirow{2}{*}{$X$} & \multicolumn{2}{|l|}{ JAK1 } & \multirow{2}{*}{ JAK2 } & \multirow{2}{*}{ JAK3 } & \multirow{2}{*}{ TYK2 } & \multicolumn{2}{|c|}{ Cellular } & \multirow{2}{*}{$\mathrm{S}+\log \mathrm{P}^{b}$} \\
\hline & & $\mathrm{pIC}_{50}$ & LE & & & & $\mathrm{pIC}_{50}$ & LLE & \\
\hline 20 & $\mathrm{~N}(\mathrm{Me}) \mathrm{SO}_{2} \mathrm{Me}$ & 7.5 & 0.42 & 7.1 & 7.5 & n.d. & 5.7 & 2.8 & 2.9 \\
\hline 21 & $\mathrm{NHSO}_{2} i-\mathrm{Pr}$ & $8.16 \pm 0.08(2)$ & 0.44 & 8.1 & 8.6 & n.d. & $6.79 \pm 0.05(2)$ & 3.3 & $3.5^{c}$ \\
\hline 22 & $\mathrm{NHSO}_{2} c-\mathrm{Pr}$ & $8.04 \pm 0.07(3)$ & 0.43 & 8.0 & 8.5 & 6.5 & $6.70 \pm 0.02$ & 3.4 & 3.3 \\
\hline 23 & $: \begin{array}{r}\mathrm{O} \\
\mathrm{H}-\stackrel{\mathrm{S}}{\|}-\end{array}$ & $7.85 \pm 0.06$ & 0.39 & 7.7 & 8.4 & 6.1 & 6.4 & 2.3 & 4.1 \\
\hline 24 & {$\left[\begin{array}{r}\mathrm{O} \\
\mathrm{H}-\stackrel{\mathrm{S}}{11}- \\
\mathrm{O}\end{array}\right.$} & $7.60 \pm 0.04$ & 0.38 & 7.6 & 8.4 & 6.4 & $6.39 \pm 0.04(3)$ & 2.3 & 4.1 \\
\hline 25 & $\mathrm{NHSO}_{2} \mathrm{CF}_{3}$ & $7.16 \pm 0.12(2)$ & 0.37 & 6.8 & 7.6 & 6.0 & $5.53 \pm 0.04(2)$ & 1.2 & 4.4 \\
\hline 26 & $\mathrm{NHSO}_{2} \mathrm{CH}_{2} \mathrm{CH}_{2} \mathrm{OH}$ & $7.94 \pm 0.13(3)$ & 0.43 & 7.7 & 8.2 & 6.2 & 6.0 & 4.0 & 1.9 \\
\hline 27 & $\mathrm{NHSO}_{2} \mathrm{CH}_{2} \mathrm{CH}_{2} \mathrm{OMe}$ & $8.03 \pm 0.15(3)$ & 0.42 & 7.8 & 8.4 & 6.3 & 6.4 & 3.6 & 2.8 \\
\hline 28 & $\mathrm{NHSO}_{2} \mathrm{CH}_{2} \mathrm{CH}_{2} \mathrm{CO}_{2} \mathrm{Me}$ & $8.26 \pm 0.15$ & 0.40 & 8.0 & 8.5 & 6.4 & 6.4 & 3.7 & 2.7 \\
\hline 29 & $: \begin{array}{r}\mathrm{O} \\
-\mathrm{N}-\stackrel{\mathrm{S}}{\mathrm{H}} \mathrm{O}\end{array}$ & $6.98 \pm 0.05(3)$ & 0.32 & 6.8 & 7.5 & 5.2 & 5.2 & 1.2 & 4.1 \\
\hline 30 & 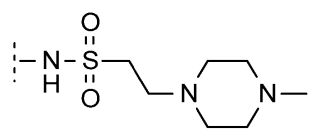 & $6.77 \pm 0.13$ & 0.30 & 6.7 & 7.2 & 5.1 & 5.1 & 2.0 & 3.2 \\
\hline 31 & $: \begin{array}{c}\mathrm{O} \\
\mathrm{N}-\mathrm{S}_{\mathrm{H}} \\
\mathrm{O}\end{array}$ & $7.78 \pm 0.07$ (2) & 0.36 & 8.1 & 8.5 & 6.5 & $6.41 \pm 0.02$ & 1.8 & 4.6 \\
\hline 32 & $-\underset{\mathrm{H}}{\mathrm{N}-\mathrm{S}_{\mathrm{O}}} \stackrel{\mathrm{N}=}{\longrightarrow}$ & $7.53 \pm 0.04(2)$ & 0.36 & 7.7 & 8.7 & 6.2 & $5.67 \pm 0.01(2)$ & 2.3 & 3.3 \\
\hline 33 & 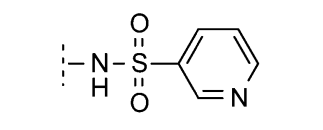 & $7.46 \pm 0.13(2)$ & 0.36 & 7.6 & 8.3 & 5.6 & 5.3 & 2.1 & 3.2 \\
\hline 34 & $\mathrm{NHSO}_{2} \mathrm{NMe}_{2}$ & $8.36 \pm 0.06(3)$ & 0.45 & 8.2 & 8.5 & 6.8 & $7.00 \pm 0.08$ & 3.9 & $3.1^{c}$ \\
\hline 35 & $\mathrm{NHP}(\mathrm{O}) \mathrm{Et}_{2}$ & $6.08 \pm 0.01$ & 0.33 & 5.5 & 6.0 & 4.7 & 4.8 & 1.5 & 3.3 \\
\hline
\end{tabular}

${ }^{a}$ Data given as $\mathrm{pIC}_{50}$ determined from single experiments with 10-point titration curves unless otherwise noted. Values from multiple determinations are given as mean \pm SEM $(N)$, where SEM is the standard error of the mean and $N$ is the number of replicates. Enzymatic assays: HTRF (Homogenous Time-Resolved Fluorescence) based kinase assay with ATP concentration at $K_{\mathrm{m}}$. Cellular assay: STAT6 reporter gene assay in a human B lymphocyte cell line (Ramos). ${ }^{b}$ Calculated using Simulations Plus, Inc. MedChem Designer. ${ }^{c}$ Experimentally determined log D at pH 7.4.

tested, but this compound was almost inactive in the cellular STAT6 assay.

Compounds 18, 19, 21, and 34 were selected for further profiling on the basis of cellular potency and LLE considerations. Because we were targeting a soft topical drug, we sought compounds with a rapid hepatic clearance.
Specifically, we targeted an intrinsic clearance in human liver microsomes greater than three times the liver blood flow rate (assumed to be $20 \mathrm{~mL} / \mathrm{min} / \mathrm{kg}$ ). The intrinsic clearances of the selected compounds are shown in Table 3; although none satisfy the softness criteria, compounds 21 and 34 were close enough to merit further investigation. 
Table 3. In Vitro PK and Toxicology

\begin{tabular}{|c|c|c|c|c|c|}
\hline \multirow[b]{2}{*}{ compd } & \multirow[b]{2}{*}{$\mathrm{Cl}_{\mathrm{int}, \mathrm{H}}{ }^{a}$} & \multicolumn{3}{|c|}{ 3T3 phototoxicity $^{b}$} & \multirow[b]{2}{*}{ hERG $\mathrm{IC}_{50}$} \\
\hline & & $+\mathrm{UV}$ & $-U V$ & PIF & \\
\hline 18 & 13 & & & & \\
\hline 19 & 17 & 14.2 & 31.9 & 2.3 & $>100 \mu \mathrm{M}$ \\
\hline 21 & 47 & & & & \\
\hline 34 & 47 & 11 & $>125$ & $>11.5$ & $>100 \mu \mathrm{M}$ \\
\hline
\end{tabular}

${ }^{a}$ Intrinsic clearance in human liver microsomes $(\mathrm{mL} / \mathrm{min} / \mathrm{kg})$. ${ }^{b}$ Cellular viability $\mathrm{IC}_{50}(\mu \mathrm{g} / \mathrm{mL})$ in the presence $(+\mathrm{UV})$ and absence $(-\mathrm{UV})$ of nontoxic doses of ultraviolet UVA irradiation, and the ratio between the two (PIF). A PIF value in the range of $2-5$ predicts probable phototoxicity, and PIF $>5$ predicts phototoxicity. ${ }^{22}$

Next, we undertook an in vitro kinome selectivity and toxicology profiling of 19 and 34. The compounds were tested in a panel of 20 tyrosine kinases ${ }^{19}$ at a single concentration chosen to be 1000 -fold their respective JAK1 $\mathrm{IC}_{50}$, see Figure 4.

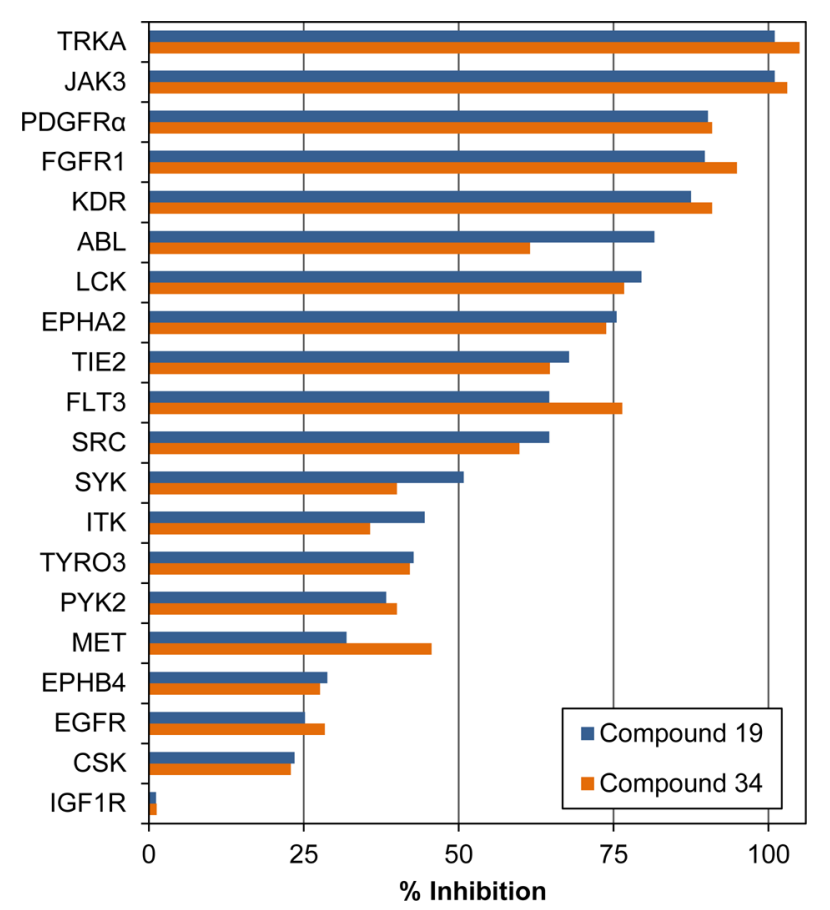

Figure 4. Tyrosine kinase panel selectivity results for compounds 19 and $34 .{ }^{19}$

Both compounds showed a similar selectivity profile with a number of off-target kinases inhibited. To quantify and compare the selectivity of these compounds, we calculated a Gini coefficient from this data. In this context, the Gini coefficient is a measure of selectivity: a completely selective inhibitor (one kinase 100\% inhibited and all others $0 \%$ inhibited) has a Gini coefficient of 1 , and a completely nonselective inhibitor (all kinases equally inhibited) has a value of $0 .^{20}$ The Gini coefficient has been shown to predict the kinome-wide selectivity of a compound from single-point panel data using as few as 20 kinases. ${ }^{20}$ We found a Gini coefficient of 0.27 for compounds 19 and 34 and a Gini coefficient of 0.71 for the highly selective JAK inhibitor tofacitinib ${ }^{21}$ in the same panel.

Compounds 19 and 34 were devoid of binding to the hERG potassium channel at $100 \mu \mathrm{M}$. Unfortunately, 19 showed probable phototoxicity and $\mathbf{3 4}$ showed clear phototoxicity in the 3T3 NRU phototoxicity test. ${ }^{22}$ Because indazole is rapidly photodegraded in aqueous solution, ${ }^{23}$ we hypothesized that the observed phototoxicity might be due to the formation of reactive or toxic photodegradation products. To determine if these compounds were degraded by light, we exposed solutions of indazole, 1, 19, and 34 to simulated outdoor light for a period of $6 \mathrm{~h}$ while monitoring the compound concentrations using LCMS. Although indazole itself was reasonably stable in this test, 1, 19, and 34 were rapidly degraded, see Figure 5. For topical use, excellent photostability is required, implying that a redesign of the scaffold to improve this property would be needed.

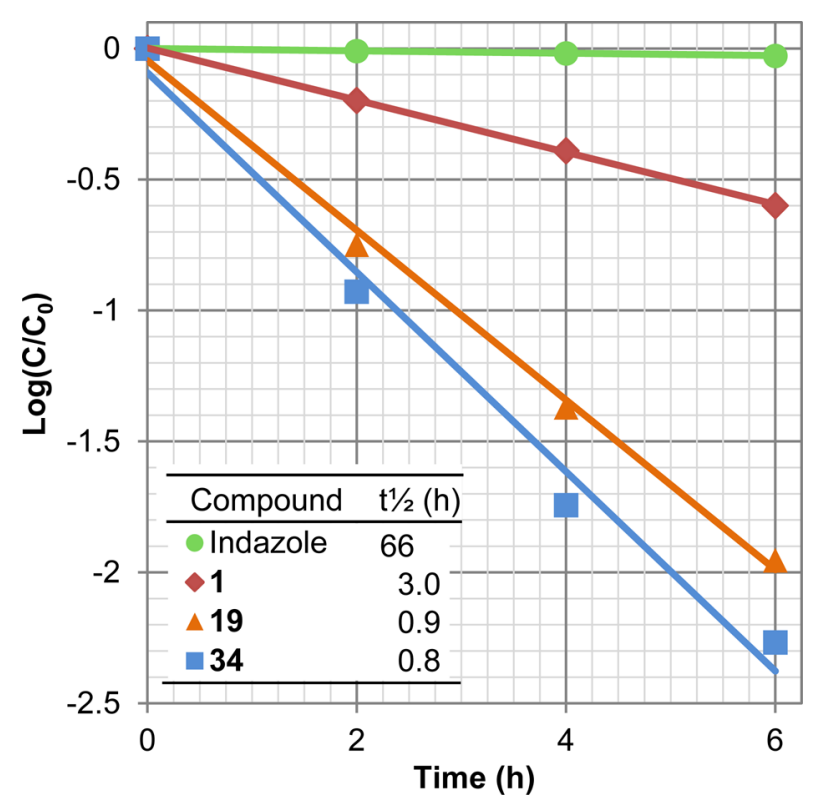

Figure 5. Photostability of indazole, 1, 19, and 34. Compounds were dissolved at $0.1 \mathrm{mg} / \mathrm{mL}$ in $1: 1 \mathrm{MeCN} /$ aqueous phosphate buffer $(\mathrm{pH}$ $=7.4$ ) and irradiated with simulated outdoor light.

In conclusion, a hit from a fragment screen was elaborated into a lead series of 6-arylindazoles. In two iterations, potency was increased by 4 orders of magnitude while preserving the excellent LE of the fragment hit. The lead compounds were moderately selective for the JAK family of tyrosine kinases and possessed in vitro PK properties consistent with our targeted soft drug profile. Poor light stability and phototoxicity deriving from the indazole core point to a need for further optimization of the scaffold.

\section{ASSOCIATED CONTENT}

\section{S Supporting Information}

The Supporting Information is available free of charge on the ACS Publications website at DOI: 10.1021/acsmedchemlett.6b00087.

Full experimental details for the compounds synthesized and descriptions of biological assays (PDF)

\section{AUTHOR INFORMATION}

\section{Corresponding Author}

*E-mail: andreas.ritzen@leo-pharma.com.

\section{Author Contributions}

A.R., M.D.S., K.N.D., and D.R.G. contributed to the design of compounds, computer modeling, and interpretation of results. 
A.J. performed the enzymatic and cell-based JAK assays and provided the kinase panel selectivity data. M.A.C. provided the intrinsic clearance data, K.A.R provided the in vitro toxicology (hERG and phototoxicity) data, and J.B.-B. performed the photostability study.

\section{Notes}

The authors declare the following competing financial interest(s): The authors are employees of LEO Pharma A/S.

\section{ACKNOWLEDGMENTS}

We gratefully acknowledge Thomas Vifian and Zhixing Wu for synthesizing the compounds presented in this paper and Paola Lovato for helpful discussions during the preparation of this manuscript.

\section{ABBREVIATIONS}

$\mathrm{AD}$, atopic dermatitis; JAK, Janus kinase; LE, ligand efficiency; LLE, ligand lipophilic efficiency; n.d., not determined; RA, rheumatoid arthritis

\section{REFERENCES}

(1) Parisi, R.; Symmons, D. P. M.; Griffiths, C. E. M.; Ashcroft, D. M. Global Epidemiology of Psoriasis: A Systematic Review of Incidence and Prevalence. J. Invest. Dermatol. 2013, 133, 377-385.

(2) Armstrong, A. W.; Robertson, A. D.; Wu, J.; Schupp, C.; Lebwohl, M. G. Undertreatment, treatment trends, and treatment dissatisfaction among patients with psoriasis and psoriatic arthritis in the United States: findings from the National Psoriasis Foundation surveys, 2003-2011. JAMA Dermatol. 2013, 149, 1180-1185.

(3) Kim, J.; Krueger, J. G. The immunopathogenesis of psoriasis. Dermatol. Clin. 2015, 33, 13-23.

(4) Kupetsky, E. A.; Mathers, A. R.; Ferris, L. K. Anti-cytokine therapy in the treatment of psoriasis. Cytokine+ 2013, 61, 704-712.

(5) Babon, J. J.; Lucet, I. S.; Murphy, J. M.; Nicola, N. A.; Varghese, L. N. The molecular regulation of Janus kinase (JAK) activation. Biochem. J. 2014, 462, 1-13.

(6) Clark, J. D.; Flanagan, M. E.; Telliez, J. B. Discovery and development of Janus kinase (JAK) inhibitors for inflammatory diseases. J. Med. Chem. 2014, 57, 5023-5038.

(7) Ghoreschi, K.; Gadina, M. Jakpot! New small molecules in autoimmune and inflammatory diseases. Exp. Dermatol. 2014, 23, 711.

(8) Hsu, L.; Armstrong, A. W. JAK inhibitors: treatment efficacy and safety profile in patients with psoriasis. J. Immunol. Res. 2014, 2014, 283617.

(9) Levy, L. L.; Urban, J.; King, B. A. Treatment of recalcitrant atopic dermatitis with the oral Janus kinase inhibitor tofacitinib citrate. J. Am. Acad. Dermatol. 2015, 73, 395-399.

(10) Bissonnette, R.; Papp, K. A.; Poulin, Y.; Gooderham, M.; Raman, M.; Papacharalambous, J.; Wang, C.; Purohit, V.; Mamolo, C.; Mallbris, L.; Ports, W. Efficacy and safety of topical Janus kinase inhibitor tofacitinib in the treatment of atopic dermatitis: results of a Phase $2 a$ randomized clinical trial. Poster presented at 23rd World Congress of Dermatology, Vancouver, Canada, June 8-13, 2015.

(11) Papp, K. A.; Menter, A.; Strober, B.; Langley, R. G.; Buonanno, M.; Wolk, R.; Gupta, P.; Krishnaswami, S.; Tan, H.; Harness, J. A. Efficacy and safety of tofacitinib, an oral Janus kinase inhibitor, in the treatment of psoriasis: a Phase $2 \mathrm{~b}$ randomized placebo-controlled dose-ranging study. Br. J. Dermatol. 2012, 167, 668-677.

(12) Ports, W. C.; Khan, S.; Lan, S.; Lamba, M.; Bolduc, C.; Bissonnette, R.; Papp, K. A randomized phase 2a efficacy and safety trial of the topical Janus kinase inhibitor tofacitinib in the treatment of chronic plaque psoriasis. Br. J. Dermatol. 2013, 169, 137-145.

(13) Bodor, N.; Buchwald, P. Soft drug design: general principles and recent applications. Med. Res. Rev. 2000, 20, 58-101.
(14) Antonysamy, S.; Hirst, G.; Park, F.; Sprengeler, P.; Stappenbeck, F.; Steensma, R.; Wilson, M.; Wong, M. Fragment-based discovery of JAK-2 inhibitors. Bioorg. Med. Chem. Lett. 2009, 19, 279-282.

(15) Wang, T.; Duffy, J. P.; Wang, J.; Halas, S.; Salituro, F. G.; Pierce, A. C.; Zuccola, H. J.; Black, J. R.; Hogan, J. K.; Jepson, S.; Shlyakter, D.; Mahajan, S.; Gu, Y.; Hoock, T.; Wood, M.; Furey, B. F.; Frantz, J. D.; Dauffenbach, L. M.; Germann, U. A.; Fan, B.; Namchuk, M.; Bennani, Y. L.; Ledeboer, M. W. Janus Kinase 2 Inhibitors. Synthesis and Characterization of a Novel Polycyclic Azaindole. J. Med. Chem. 2009, 52, 7938-7941.

(16) Wang, T.; Ledeboer, M. W.; Duffy, J. P.; Pierce, A. C.; Zuccola, H. J.; Block, E.; Shlyakter, D.; Hogan, J. K.; Bennani, Y. L. A novel chemotype of kinase inhibitors: Discovery of 3,4-ring fused 7azaindoles and deazapurines as potent JAK2 inhibitors. Bioorg. Med. Chem. Lett. 2010, 20, 153-156.

(17) Beno, B. R.; Yeung, K.-S.; Bartberger, M. D.; Pennington, L. D.; Meanwell, N. A. A Survey of the Role of Noncovalent Sulfur Interactions in Drug Design. J. Med. Chem. 2015, 58, 4383-4438.

(18) Coe, J. W.; Dehnhardt, C. M.; Jones, P.; Kortum, S. W.; Sabnis, Y. A.; Wakenhut, F. M.; Whitlock, G. A. Indazoles. PCT Pat. Appl. WO2013014567, Jan. 31, 2013.

(19) Carna Biosciences, Inc. QuickScout TK Panel; assay ATP concentration at $K_{\mathrm{M}}$ of the respective enzyme.

(20) Graczyk, P. P. Gini Coefficient: A New Way To Express Selectivity of Kinase Inhibitors against a Family of Kinases. J. Med. Chem. 2007, 50, 5773-5779.

(21) Davis, M. I.; Hunt, J. P.; Herrgard, S.; Ciceri, P.; Wodicka, L. M.; Pallares, G.; Hocker, M.; Treiber, D. K.; Zarrinkar, P. P. Comprehensive analysis of kinase inhibitor selectivity. Nat. Biotechnol. 2011, 29, 1046-1051.

(22) A thorough description of the assay can be found in OECD (2004), Test No. 432: In Vitro 3T3 NRU Phototoxicity Test, OECD Guidelines for the Testing of Chemicals, Section 4; OECD Publishing: Paris.

(23) Janssen, E. M. L.; Marron, E.; McNeill, K. Aquatic photochemical kinetics of benzotriazole and structurally related compounds. Environ. Sci.: Processes Impacts 2015, 17, 939-946. 